\title{
The Learnability Criterion and Monetary Policy
}

\author{
James B. Bullard
}

\begin{abstract}
Expectations of the future play a large role in macroeconomics. The rational expectations assumption, which is commonly used in the literature, provides an important benchmark, but may be too strong for some applications. This paper reviews some recent research that has emphasized methods for analyzing models of learning, in which expectations are not initially rational but which may become rational eventually provided certain conditions are met. Many of the applications are in the context of popular models of monetary policy. The goal of the paper is to provide a largely nontechnical survey of some, but not all, of this work and to point out connections to some related research.
\end{abstract}

Federal Reserve Bank of St. Louis Review, May/June 2006, 88(3), pp. 203-17.

\section{INTRODUCTION}

\section{Overview}

$\mathrm{n}$ a number of recent papers, economists have begun to analyze the stability of rational expectations equilibria under learning in microfounded models of monetary policy. Most of these analyses have been in versions of the New Keynesian macroeconomics, as presented most prominently by Woodford (2003a). The goal of this paper is to provide a brief, largely nontechnical survey of some, but not all, of this work and to point out connections to some related research.

\section{Origins}

Learning has been an issue in macroeconomics since the rational expectations revolution swept the field in the 1970s and 1980s. Rational expectations has long been understood as a modeling device: When studying economic outcomes, we economists should think of them as equilibria only if expectations are consistent with actual outcomes. But, how is it that economic actors could come to possess rational expectations if they do not initially possess detailed knowledge concerning the nature of equilibrium in the economy or economic situation in which they find themselves? ${ }^{1}$

Several key papers in the 1980s, including Bray (1982), Evans (1985), Lucas (1987), and Marcet and Sargent (1989a,b), explored an idea concerning one resolution of this question. The idea was that, indeed, economic actors cannot be expected to initially know the nature of the equilibrium of the economy in which they operate. Instead, they have a perception of the equilibrium law of motion, and they use available data generated by the economy itself to update their perceived law of motion using recursive algorithms,

1 Some of the tenor of the earlier, feisty debate on this question is conveyed by the following quote from an influential paper by Stephen DeCanio (1979, p. 52, italics in original): “Thus, direct computation of rational expectations by flesh-and-blood agents in an actual market situation is impossible in practice."

James B. Bullard is a vice president and economist at the Federal Reserve Bank of St. Louis. This paper is a revised and extended version of remarks originally prepared for the conference, "Heterogeneous Information and Modelling of Monetary Policy," held in Helsinki, Finland, October 2-3, 2003. The author thanks the Bank of Finland and the Center for Economic Policy Research for sponsoring this event, and Seppo Honkapohja, Massimo Guidolin, and Michael Owyang for helpful comments. Deborah Roisman provided research assistance.

(C) 2006, The Federal Reserve Bank of St. Louis. Articles may be reprinted, reproduced, published, distributed, displayed, and transmitted in their entirety if copyright notice, author name(s), and full citation are included. Abstracts, synopses, and other derivative works may be made only with prior written permission of the Federal Reserve Bank of St. Louis. 
such as recursive least squares. Should the perceived law of motion come to coincide with the actual law of motion of the economy, a rational expectations equilibrium will have been attained. The economic actors will have "learned" the rational expectations equilibrium.

This idea also has an appealing practical interpretation. In an actual macroeconomic environment, expectations of all of the key players are influenced by the expectations of the forecasting community. The forecasting community uses econometric models of the economy, recursively updated. Thus, it is not too far-fetched to think that a dynamic like the one described is powerful and at work in observed macroeconomies.

The question of whether such a process will actually converge or not is technically demanding because, in economic models, beliefs concerning the future help determine actual values of key variables; but, under learning, these same values are used in the recursive updating and so feed back into the generation of updated beliefs. It is not at all clear how such a system should be expected to behave. The findings of Marcet and Sargent $(1989 a, b)$ on this question were revised, extended, and explored in a series of papers by George Evans and Seppo Honkapohja during the 1990s. Much of that effort is discussed in the landmark book by Evans and Honkapohja (2001), where they present a complete theory of the effects of recursive learning in macroeconomic environments. One theme of their theory is that local convergence in such systems can often be assessed by calculating a certain expectational stability (E-stability) condition, viewing the mapping from the perceived law of motion to the actual law of motion as a differential equation in notional time. They show the conditions under which the stability of this differential equation governs the stability of the system under real-time recursive learning. ${ }^{2}$ These conditions are generally quite weak, and so many authors now routinely calculate expectational stability conditions as a means of assessing stability under recursive learning in models of interest.

2 The systems under real-time learning are stochastic difference equations with time-varying coefficients.

\section{A Minimal Criterion}

It is important to stress that the idea of stability under recursive learning-learnability-just outlined can be viewed as a "minimal deviation from rational expectations" approach to this question. The agents in the model are endowed with a perceived law of motion which, in most cases, corresponds in form to the equilibrium law of motion for that economy. Thus, the agents are given the correct specification for their recursively estimated vector autoregressions that they use to forecast the future. In addition, the theorems are local in nature, so that we think of the systems as initially quite near the rational expectations equilibrium. And, the agents are passive updaters-they simply update the coefficients in their model as new data are produced. Convergence hinges on whether initially small expectational errors are damped or magnified as the economy evolves. One interpretation of this is that the situation is very favorable to allowing the agents to learn the rational expectations equilibrium. If the equilibrium cannot be learned even under these very favorable conditions, then one might be quite pessimistic about the possibility of observing such an equilibrium in an actual economy. Thus, the learnability criterion can be viewed as a minimal stability condition that any reasonable equilibrium should be required to meet.

\section{What Has Been Learned So Far?}

The main messages of the learning literature to date are not difficult to summarize. First and foremost, it is possible in many macroeconomic environments that recursive learning as described above can produce a dynamic that converges to a rational expectations equilibrium. So, some rational expectations equilibria are indeed learnable in this sense. Some initial thinking on this issue suggested that a general case could be made for nonconvergence, and thus that rational expectations equilibrium was not a useful concept. But that argument has been dispelled.

A second message, however, is that not all rational expectations equilibria are learnable. Some, in fact, are unstable under the recursive learning dynamic. Furthermore, because this con- 
ception of recursive learning involves a minimal deviation from rational expectations, the unlearnable equilibria are particularly suspect as descriptions of actual economies. One certainly has the impression from much of the economics profession that all rational expectations equilibria are somehow learnable, ${ }^{3}$ but it turns out not to be true. It is perhaps not hard to imagine now that, for systems like this, the feedback could be too strong and expectational errors could be amplified.

The state of affairs is thus that some rational expectations equilibria are learnable while others are not. Furthermore, convergence will in general depend on all the economic parameters of a given system, including the policy parameters (that is, it depends on the entire economic structure). Therefore, an important additional message is that policy can have an impact on whether a targeted rational expectations equilibrium is learnable or not. Policymakers therefore may wish to take into account how a particular policy choice might influence the stability of a targeted equilibrium. This feature of the recent literature has generated considerable interest.

One additional message is that there appears to be no clear, general relation between conditions for learnability and conditions for determinacy of rational expectations equilibrium. I will discuss this issue briefly below.

\section{Alternative Formulations of Learning}

In a recent after-dinner speech, eminent economist Charles Goodhart remarked that, in his opinion, most learning in a large macroeconomy comes not from statistical regression of any kind, but from information passed from person to person. Goodhart said, "You ask your uncle."4 That comment certainly rings true and echoes a longstanding criticism of the learning literature as I have described it. But learning along this line has also been pursued in the macroeconomics and finance literature.

A key aspect of the Goodhart comment is that important economic judgment travels from

\footnotetext{
3 This seems to be the message in Lucas (1987).

4 I am paraphrasing a portion of the remarks by Goodhart (2003).
}

person to person, leaving different people in the population with different beliefs most of the time. As an example, consider an individual decision that has important implications for macroeconomics: How much should a household save out of current income, and how should savings be allocated among available assets? It seems undeniable that in actual economies, households obtain information to help them answer these questions by asking those around them and by obtaining professional advice. Households with similar characteristics often have very different savings strategies. This would seem to conflict with most models, in which behavior and expectations are homogeneous.

The artificial intelligence literature has produced some models that can address some of these issues. ${ }^{5}$ The ones that have been investigated in economic contexts are often variants of genetic algorithms. Some prominent examples in the literature include Marimon, McGrattan, and Sargent (1990) and Arifovic (1996). In these models, a standard economic environment is assumed, but agents are allowed to hold initially diverse beliefs concerning a key future variable, such as an expected rate of return on an asset. Agents then make optimal decisions given their expectations, which, aggregated over all of the agents in the economy, produces some actual outcomes-prices and quantities - for the current period. Agent beliefs are then updated using genetic operators. These operators draw on evolutionary principles. First, beliefs that deliver low utility to their owners tend to get replaced with beliefs that deliver higher utility. In addition, agents experiment with alternative beliefs, either ones that are mixes of their own and those of other agents in the economy, ${ }^{6}$ called crossover, or simply by means of a random change in belief, called mutation. With a new set of beliefs in place, new decisions are made, and new outcomes are produced. The question is then: Will such a process converge to a rational expectations equilibrium of the model?

\footnotetext{
5 Heterogeneity and learning have been addressed outside the artificial intelligence literature as well. See, for instance, Branch and Evans (2006), Giannitsarou (2003), and Guse (2005).

6 This operator relates to Goodhart's comment.
} 
The papers in the evolutionary learning literature for macroeconomics tend to be computational, as few analytical results are available. The short answer is that, yes, processes like the one I have described can converge to rational expectations equilibria of well-defined models. And again, not all rational expectations equilibria are stable under this type of learning dynamic. ${ }^{7}$ The genetic algorithm approach departs from the "minimal deviation from rational expectations" ideal of the recursive learning literature and asks the learning dynamic to describe a global search for equilibrium from initial agent behavior that might be nearly random. In this sense, the approach is much more ambitious. It is also more attractive as a model of the type of social learning that seemingly takes place every day in observed macroeconomies. The genetic algorithm approach also puts heavy emphasis on how information diffuses across households in an economy. The nature of the information diffusion is based on the properties of the genetic operators that are assumed. ${ }^{8}$

\section{Relation to Behavioral Finance}

Sometimes learning is mentioned in conjunction with the burgeoning behavioral finance literature. ${ }^{9}$ The behavioral finance approach draws on psychology, especially experiments with human subjects, to document behavior patterns. Take the following case of subjects who undergo observation in psychological studies. They may seem to be persistently pessimistic, for example, during the course of the study. The literature would then seek to postulate these behaviors in models to see whether apparent anomalies in financial data can then be explained. ${ }^{10}$ The behavioral finance approach, then, is quite different from the learning literature as I have described it. The macroeconomics learning literature asks how rational

\footnotetext{
7 The Arifovic (1996) paper, for instance, describes a process that does not converge and instead produces endogenously fluctuating exchange rates.

${ }^{8}$ For a survey of this literature, see Arifovic (2000).

9 For one summary of work in behavioral finance, see VissingJorgensen (2004).

${ }^{10}$ These ideas are not so new; see the volume by Hogarth and Reder (1987).
}

expectations could come about, allowing that agents behave optimally given their expectations. The behavioral finance literature seeks to understand the empirical implications of postulating certain types of seemingly irrational, but laboratory documented, behavior on the part of market participants. A natural question, and one that is sometimes asked, is whether the seemingly irrational behavior can survive over a long period of time or whether instead market participants would learn the rational behavior. Thus, learning is often mentioned in conjunction with behavioral finance, and this seems to be a fruitful area of future research.

\section{LEARNABILITY IN MONETARY POLICY MODELS}

\section{Taylor-Type Policy Rules}

Consider a small, closed, New Keynesian economy described by Woodford (1999 and 2003a) and Clarida, Galí, and Gertler (1999):

$$
\begin{gathered}
z_{t}=\hat{E}_{t} z_{t+1}-\sigma^{-1}\left[r_{t}-\hat{E}_{t} \pi_{t+1}\right]+r_{t}^{n}, \\
\pi_{t}=\kappa z_{t}+\beta \hat{E}_{t} \pi_{t+1} .
\end{gathered}
$$

These equations are derived from a model in which each infinitely lived member of a continuum of household-firms produces a differentiated good using labor alone, but consumes an aggregate of all goods in the economy. The household-firms price their good under a constraint on the frequency of price change. The first-order conditions for the consumption problem yield equation (1) while those for the pricing problem yield equation (2). The variable $\pi_{t}$ is the percentage-point time- $t$ deviation of inflation from a fixed target value; $z_{t}$ is the output gap, also in percentage points; $r_{t}^{n}$ is an exogenous shock, usually thought of as being serially correlated; and $r_{t}$ is the deviation of the short-term nominal interest rate from the value consistent with inflation at target and which is under the control of the monetary authority. The parameter $\beta$ is the common discount factor of the households, $\sigma$ relates to the elasticity of intertemporal substitution in consumption of the 
household, and $\kappa$ relates to the degree of price stickiness in the economy. These parameters are argued to be invariant to contemplated changes in policy. Bullard and Mitra (2002) view the inflation target and the long-run level of output as zero. The notation $\hat{E}_{t}$ is meant to indicate a possibly nonrational expectation taken using information available at date $t$, so that $E_{t}$ without the hat is the normal expectations operator. ${ }^{11}$ To close the model, one might postulate a simple monetary policy feedback rule of the type discussed by Taylor (1993) and analyzed in the large literature since that paper was published. One could write such a rule as

$$
r_{t}=\varphi_{\pi} \pi_{t}+\varphi_{z} z_{t},
$$

where $\varphi_{\pi}$ and $\varphi_{z}$ are nonnegative and not both equal to zero. The parameters in the policy rule are particularly interesting as they may have an impact on the nature of the rational expectations equilibrium of the model, and they may also have an impact on the ability of the private sector agents to learn a rational expectations equilibrium.

One interesting feature of this model is that expectations enter on the right-hand side of equations (1) and (2). This is a consequence of the microfoundations, in which the household-firms are forward-looking in deciding today's consumption and today's prices. This would seem to be an inescapable consequence of the microfounded approach; therefore, we might expect all monetary policy models to have this feature in some form, and thus that the type of analysis discussed below should apply to a wide variety of models of monetary policy and not only to the simple example given here.

Bullard and Mitra (2002) studied the model (1)-(3) under both a rational expectations assumption and under a learning assumption using the approach of Evans and Honkapohja (2001). Under rational expectations, a key question is whether rational expectations equilibrium is unique, a.k.a.

\footnotetext{
${ }^{11}$ The microfoundations of the model were developed assuming rational expectations. Preston (2005) has argued that these equations would change under some interpretations of the microfoundations when agents are learning. But Evans, Honkapohja, and Mitra (2003) have argued that, under some reasonable assumptions, these equations would remain unaltered.
}

determinate. To calculate determinacy properties, substitute (3) into (1) and write the resulting system in matrix form as

$$
y_{t}=\alpha+B \hat{E}_{t} y_{t+1}+\aleph r_{t}^{n},
$$

with $y_{t}=\left[z_{t}, \pi_{t}\right]^{\prime}, \alpha=0, \aleph$ is a conformable matrix that is not needed in the calculations below, and

$$
B=\frac{1}{\sigma+\varphi_{z}+\kappa \varphi_{\pi}}\left(\begin{array}{cc}
\sigma & 1-\beta \varphi_{\pi} \\
\kappa \sigma & \kappa+\beta\left(\sigma+\varphi_{z}\right)
\end{array}\right)
$$

Both $z_{t}$ and $\pi_{t}$ are free variables in this system, and so both eigenvalues of $B$ need to be inside the unit circle for determinacy to hold. ${ }^{12}$ Bullard and Mitra (2002) show that the condition for determinacy is

$$
\varphi_{\pi}+\frac{(1-\beta)}{\kappa} \varphi_{z}>1
$$

This condition is a statement of the Taylor principle, as discussed by Woodford (2001 and 2003a). From equation (2), a permanent increase in inflation increases the output gap by $(1-\beta) / \kappa$ percentage points. Then, given equation (3), the left-hand side of (6) can be interpreted as the extent of the long-run increase in the nominal interest rate in response to a permanent change in inflation. The condition (6) states that this response must be greater than 1, that is, that nominal interest rates must rise more than one-for-one with inflation to achieve determinacy of equilibrium.

Even when determinacy obtains, however, the question of learnability still needs to be decided. To calculate learnability, Bullard and Mitra (2002) postulated a perceived law of motion for the private sector given by

$$
y_{t}=a+c r_{t}^{n},
$$

where $a$ is a $2 \times 1$ vector and $c$ is a $2 \times 2$ matrix. This perceived law of motion corresponds in form to the minimal state variable solution to equation (4) and thus endows the agents with the correct specification of the rational expectations equilibrium. Under this perceived law of motion, agent expectations are given by

\footnotetext{
${ }^{12}$ Blanchard and Kahn (1980).
} 


\section{Figure 1}

\section{Policy Rules with Contemporaneous Data}

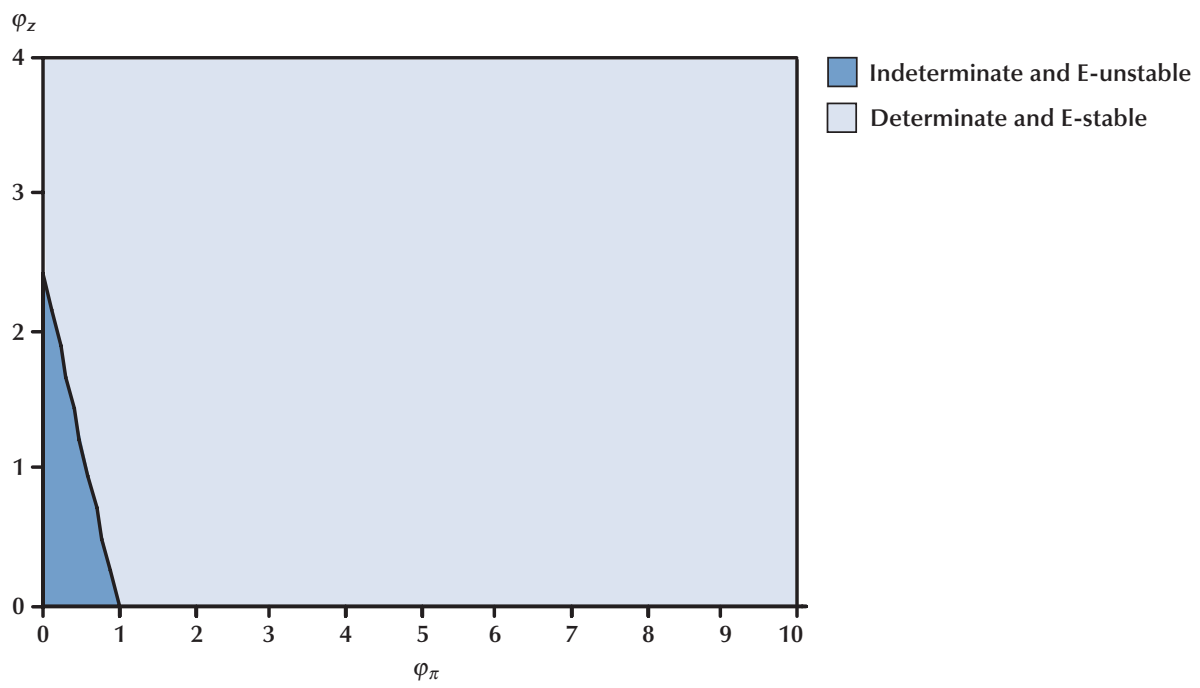

NOTE: Regions of determinacy and expectational stability for the class of policy rules using contemporaneous data. Parameters other than $\varphi_{\pi}$ and $\varphi_{z}$ are set at baseline values. Reprinted with permission from Bullard and Mitra (2002).

(8)

$$
E_{t} y_{t+1}=a+c \rho r_{t}^{n},
$$

where $\rho$ is the serial correlation parameter for the shock $r_{t}^{n}$. Substituting equation (8) into equation (4) yields the actual law of motion given the perceptions in equation (7), namely,

$$
y_{t}=B a+(B c \rho+\aleph) r_{t}^{n} .
$$

Equations (7) and (9), the perception and the reality, respectively, together define a map, $T$, as

$$
T(a, c)=(B a, B c \rho+\aleph) .
$$

Expectational stability is determined by the matrix differential equation

$$
\frac{d}{d \tau}(a, c)=T(a, c)-(a, c) .
$$

If the differential equation (11) is asymptotically stable at the fixed point $(\bar{a}, \bar{c})$ the system is said to be expectationally stable.

A key result in Bullard and Mitra (2002) is to show that the condition for expectational stability in this system is exactly the inequality (6). As has been argued, this condition corresponds exactly to the Taylor principle applied to this system. Thus, the Taylor principle delivers both determinacy and learnability for a standard New Keynesian model. ${ }^{13}$ It would seem to be good advice to give to policymakers, both from the point of view of uniqueness of equilibrium and from the point of view of achievability of that equilibrium, that they adopt the Taylor principle in selecting a particular policy rule-values for $\varphi_{\pi}$ and $\varphi_{z}$-in this model.

This key result is summarized in Figure 1 from Bullard and Mitra (2002), where parameter values other than those in the policy rule have been set at the calibration values recommended by Woodford (1999). The message of Figure 1 is that, so long as the monetary authority chooses a pair of values, $\varphi_{\pi}$ and $\varphi_{z}$, that are sufficiently large, or "aggressive," then the economy will possess an equilibrium that is both unique and learnable. Should the policymaker choose values in such a

\footnotetext{
${ }^{13}$ For some further discussion of the connections between the conditions for determinacy and those for learnability in this model, see Woodford (2003a,b).
} 


\section{Figure 2}

\section{Policy Rules with Lagged Data}

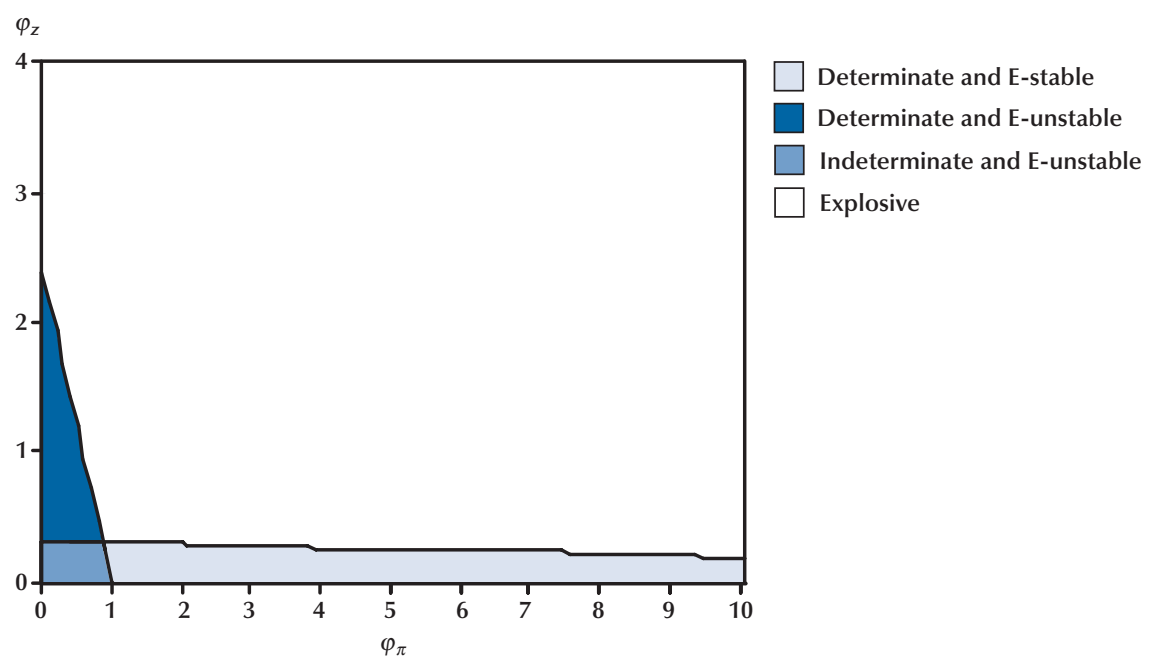

NOTE: Determinacy and learnability for rules responding to lagged data, with parameters other than $\varphi_{\pi}$ and $\varphi_{z}$ set at baseline values. Determinate equilibria may or may not be E-stable. Reprinted with permission from Bullard and Mitra (2002).

way that the Taylor principle (6) is violated, then determinacy does not obtain and unexpected outcomes may arise. Among the pairs of $\varphi_{\pi}$ and $\varphi_{z}$ that deliver determinacy and learnability, policymakers can apply other criteria, such as the expected utility of the representative household, to decide on an optimal policy.

More information can be gleaned from Figure 1, however. Under rational expectations, once one demonstrates that a determinate equilibrium exists, there is little further to discuss, other than the quantitative nature of the equilibrium itself. Under learning, however, there is more to the story, because even within the determinate and learnable region, the choice of the parameters in the policy rule will influence the speed with which the private sector can learn the rational expectations equilibrium. This issue has been analyzed in Ferrero (2004). Some policy choices may involve learning times that are extremely long, and hence policymakers may wish to think twice about adopting them.

Figure 1 would seem to suggest that determinacy and learnability go hand in hand, but this is not the case. Consider the alternative policy rule defined by

$$
r_{t}=\varphi_{\pi} \pi_{t-1}+\varphi_{z} z_{t-1}
$$

Here the monetary authority reacts to last period's values of inflation deviations and the output gap, perhaps because of realistic information lags. As McCallum (1999) has emphasized, central banks do not observe inflation or the output gap in the same quarter in which they must make decisions regarding their short-term nominal interest rate target. Bullard and Mitra (2002) show that this case is more complicated and in fact that the conditions for determinacy and learnability do not align. This result is shown in Figure 2. The conclusion is that determinacy does not imply learnability. The darkest region in the figure indicates a situation where the policy rule generates determinacy, but not learnability.

The policy rules that have been considered so far have the monetary authority reacting to current or past developments concerning key economic variables. But one might imagine that central banks are forward-looking, so that they 
react not to current or past data directly, but to their own forecast of future developments, say, one period in the future. This case can also be analyzed, assuming that both the private sector and the central bank learn in exactly the same way. Bullard and Mitra (2002) calculate determinacy and learnability conditions in this case and find that the two criteria do not coincide when central banks are forward-looking. ${ }^{14}$

In a closely related paper, Bullard and Mitra (2006) consider the more complicated, but more realistic, situation when the central bank also includes a lagged interest rate in its policy rule,

$$
r_{t}=\varphi_{\pi} \pi_{t-1}+\varphi_{z} z_{t-1}+\varphi_{r} r_{t-1},
$$

with $\varphi_{r}>0$. They come to the conclusion that policy inertia tends to improve the prospects for both determinacy and learnability. This might provide some part of an explanation as to why empirical estimates of actual central bank behavior put important weight on the lagged value of the short-term nominal interest rate. ${ }^{15}$

\section{Optimal Policy Rules}

Svensson (2003) has argued that postulating Taylor-type monetary policy rules, even with open coefficients ${ }^{16}$ as in Rotemberg and Woodford (1999), is not a satisfactory practice. Instead, the monetary authority should be modeled as having an objective that they wish to accomplish as best they can with the instruments at their disposal and under the constraints imposed on them by the economic environment. Such an approach would imply "a more complex reduced-form reaction function" (Svensson, 2003, p. 14). One could argue with this conception. By specifying a class of linear policy feedback rules, the analysis can isolate conditions for determinacy and learnability for rules within the class-and then calcu-

\footnotetext{
${ }^{14}$ For a recent analysis of the related issue of constant interest rate forecasts on the part of central banks, see Honkapohja and Mitra (2005).

15 Typical estimates in the literature put the value of $\varphi_{r}$ at 0.7 or even 0.9 , depending on the country and the time period.

16 That is, without assigning specific numerical values. Rotemberg and Woodford (1999) indeed found optimal policy rules, but within classes of possible rules that look like the ones Taylor discussed, such as (13).
}

late an optimal rule from among the ones that satisfy the determinacy and learnability conditions according to any criterion one wishes to ascribe to the policymaker. By specifying policymaker behavior according to a given objective first, one risks specifying a policy rule that generates indeterminacy, unlearnability, or both.

One example of this phenomenon occurs in Evans and Honkapohja (2006 and 2003a,b). They considered the economy described by equations (1) and (2) but replaced (3) with an explicit optimization problem for the monetary authorities to solve. This problem can be viewed as policymakers attempting to maximize

$$
E_{t} \sum_{s=0}^{\infty} \beta^{s}\left[\pi_{t+s}^{2}+\alpha z_{t+s}^{2}\right]
$$

where $\beta$ is the discount factor used by policymakers (assumed to be the same as the discount factor used by the private sector) and the relative weight on output versus inflation is given by $\alpha$, with $\alpha=0$ corresponding to the "strict inflation targeting" case. ${ }^{17}$ The inflation target is again assumed to be zero. It is well-known that the firstorder conditions for this problem differ depending on whether one assumes a discretionary central bank or one that is able to commit to a superior policy by taking a timeless perspective. ${ }^{18}$ Under discretion the first-order condition is

$$
\kappa \pi_{t}+\alpha z_{t}=0
$$

whereas under commitment it is

$$
\kappa \pi_{t}+\alpha\left(z_{t}-z_{t-1}\right)=0 .
$$

Evans and Honkapohja (2006 and 2003a,b) stress that one still needs an interest rate reaction function to implement the policy, and, importantly, there are many such functions that will implement the optimal policy under rational expectations. Do all of these possible reaction functions induce equilibria with the same determinacy and learnability properties? In fact, they

\footnotetext{
${ }^{17}$ Woodford (2003a) has argued that objective (14) approximates the utility of the representative household, in which $\alpha$ takes on a specific value.

18 See Woodford (2003a).
} 
do not. One might consider the "fundamentalsbased" optimal policy—that is, an interest rate rule that calls for instrument adjustments directly in response to the fundamental shocks. ${ }^{19}$ One can write down such a rule for either the discretionary or the commitment case. The startling result of Evans and Honkapohja (2003a) is that interest rate reaction functions of this type invariably imply that the equilibrium is unstable in the learning dynamics. Equilibrium is also always indeterminate. Evans and Honkapohja (2003b) label this finding "deeply worrying," and, indeed, the analysis shows the dangers of proceeding naively from the objective (14) to an implementable policy without considering the effects of that policy on the nature of equilibrium or the stability of the equilibrium in the face of small expectational errors.

However, equilibrium can be rendered both determinate and learnable with an alternative interest rate feedback rule, as Evans and Honkapohja (2003a) show. This alternative rule still implements the optimal policy according to the objective (14), but it does so in a way that creates a determinate and learnable equilibrium. The key is to augment the set of variables included on the right-hand side of the feedback rule to include private sector expectations of key variables (the output gap and inflation) as well as the fundamental shocks of the model. This alternative representation of the optimal policy rule is successful in generating determinacy and learnability because it does not assume the private sector has rational expectations, instead allowing the central bank to react to small expectational errors. Of course, for this type of policy rule to be of importance in actual economies, one has to assume that private sector expectations are observable. ${ }^{20}$

\section{Learning Sunspots}

With the rational expectations revolution came the idea of sunspot, or nonfundamental, equilibria, in which homogeneous expectations

\footnotetext{
${ }^{19}$ For one discussion, see Clarida, Galí, and Gertler (1999).

20 The Evans and Honkapohja (2006 and 2003a,b) results are sensitive to the specification of the objective function. If one includes interest rate deviations in the objective, E-stability can be achieved without requiring the monetary authority to react to private sector expectations. See Duffy and Xiao (2005).
}

are conditioned on purely extrinsic uncertainty, that would not matter for the economy except that agents do condition their expectations on it. This idea has had considerable success as interpretations of many macroeconomic events seem to be consistent with the idea of self-fulfilling expectations. A general finding in the theory literature is that sunspot equilibria exist when equilibrium is indeterminate, so that indeterminacy can imply both the existence of multiple, fundamental equilibria and also the existence of additional, nonfundamental sunspot equilibria. But could agents actually learn such equilibria, in the sense we have described here? To do so, the agents would need to have a perceived law of motion that is consistent with the possibility of a sunspot variable playing an important role.

In a classic paper, Woodford (1990) addressed this question and argued that, indeed, a simple recursive learning dynamic might lead agents to coordinate on a sunspot equilibrium. His environment was a version of the overlapping generations model. Honkapohja and Mitra (2004) carry out an analysis of the learnability of nonfundamental equilibria in models like the one described in equations (1)-(3). They find that the Taylor principle continues to play an important role in the learnability of nonfundamental equilibria. In their analysis, violations of the Taylor principle tend to imply indeterminacy, and none of the equilibria are learnable in those cases. Thus, violation of the Taylor principle would seem to imply that the private sector cannot coordinate on a rational expectations equilibrium of any kind in the context of the New Keynesian model. ${ }^{21}$ This idea turns out not to completely characterize the situation, however. Evans and McGough (2005) show that sunspot equilibria may indeed be learnable if one focuses on common factor representations of the sunspot solution.

The tendency in the monetary policy literature, and indeed in the macroeconomics theory literature generally, has been to regard the case of indeterminacy and possible sunspot equilibria as a situation to be avoided at all costs. If a par-

\footnotetext{
${ }^{21}$ Similar results occur in a real business cycle context with indeterminacy. The sunspot equilibria that exist there are generally not learnable, as shown by Duffy and Xiao (2006).
} 
ticular policy generates indeterminacy, then in the eyes of most authors the policy is not a desirable one, quite apart from any question concerning learnability of equilibrium. A dissenter from this view is McCallum (2003), who argues that when multiple equilibria exist, only fundamental, minimal state variable solutions are likely to be observed in practice, and thus arguments based on the mere existence of many nonfundamental equilibria should be given less weight in the literature. A portion of his argument is that nonfundamental equilibria are unlikely to be learnable. In discussing McCallum, Woodford (2003b) argues that, because in the indeterminate cases the minimal state variable solution is also often not learnable, as in the Honkapohja and Mitra (2004) analysis, one should not rely solely on the minimal state variable criterion in generating a "prediction" from a given model.

\section{LEARNABILITY IN RELATED MODELS}

\section{Liquidity Traps}

The fact that Japan has experienced zero or near-zero short-term nominal interest rates for several years has rekindled ideas about liquidity trap equilibria originally discussed in the 1930s. Benhabib, Schmitt-Grohé, and Uribe (2001) presented an influential analysis of this situation. They argued that the combination of a zero bound on nominal interest rates, commitment of the monetary authority to an active Taylor rule (that is, one that follows the Taylor principle) at a targeted level of inflation, and a Fisher relation generally implies the existence of a second steadystate equilibrium. This second steady state is characterized by low inflation (lower than the target level) and low nominal interest rates in a wide class of monetary policy models currently in use. The Taylor principle does not hold at the lowinflation steady state. They also showed, in the context of a specific economy, the existence of equilibria in which interest rates and inflation are initially in the neighborhood of the targeted inflation rate, but which leave that neighborhood and converge to the low-inflation steady state. From the perspective of the literature on expectational stability, a natural question is, Which of the steady-state equilibria presented by Benhabib, Schmitt-Grohé, and Uribe (2001) are learnable?

Based on the results presented so far, in which the Taylor principle governs convergence under recursive learning, one might expect that the targeted, high-inflation equilibrium (in which the Taylor principle holds) would be stable under recursive learning, while the low-inflation equilibrium would not be. Evans and Honkapohja (2005) analyze versions of the Benhabib et al. (2001) economy in which this logic generally holds. The monetary authority in Evans and Honkapohja (2005) can switch to an aggressive money supply rule at low rates of inflation, and this switch can support a third steady state characterized by an even lower inflation rate. This steady state can be learnable in their analysis, and in this sense they find a learnable liquidity trap. But if the monetary authority switches to the money supply rule in support of an inflation rate that is sufficiently high, then the economy is left with only the targeted, relatively high-inflation steady state as a learnable equilibrium.

Another analysis of this issue is by Eusepi (2005), who also finds some instances of a learnable liquidity trap in a model with a forecast-based interest rate rule. Eusepi (2005) also provides an analysis of the nonlinear dynamics of this model under learning. As a border of a stable region of the parameter space is approached (say, as a particular policy parameter is increased), an eigenvalue crosses the unit circle, which is normally a defining feature of a local bifurcation. The system can then display cycles and other stationary behavior in a neighborhood of the steady state. Eusepi (2005) finds that this type of outcome can occur in versions of the model studied by Benhabib, Schmitt-Grohé, and Uribe (2001) under learning. ${ }^{22}$

\footnotetext{
${ }^{22}$ Models with multiple steady states are a natural laboratory for the study of learning issues, independent of questions about liquidity traps. A recent example is Adam, Evans, and Honkapohja (2006).
} 


\section{The Role of Escape Dynamics}

An alternative approach to low nominal interest rate outcomes is studied in Bullard and Cho (2005). Their model is linear and possesses a unique equilibrium in which inflation is near target at all times. To explain persistently, and unintentionally, low nominal interest rates, they design their model to produce an "escape" from the unique equilibrium toward a nonequilibrium focal point, which is characterized by low nominal interest rates and low inflation. The systems they study tend to return to the unique equilibrium following these episodes of "large deviations." Thus, the Bullard and Cho (2005) approach to low nominal interest rate outcomes does not involve the economy being permanently stuck in a liquidity trap. To generate the escape dynamics, Bullard and Cho (2005) rely on the following features: (i) The private sector has a certain misspecified perceived law of motion for the economy;

(ii) there is feedback from the beliefs of the private sector to the actions of the monetary authority; and (iii) the private sector uses a constant gain learning algorithm, which puts more weight on recent observations and less weight on past observations when obtaining key estimates of parameters by means of recursive learning.

Students of escape dynamics will recognize the elements just described from themes in Sargent (1999), Cho, Williams, and Sargent (2002), Kasa (2004), Sargent and Williams (2005), and Williams (2001). The escape dynamics in a learning model are interesting because they describe a situation in which the economy is at or near rational expectations equilibrium most of the time, but in which rare events can endogenously push the economy away from the equilibrium toward persistent nonequilibrium outcomes. This may be quite valuable in helping economists understand unusual, but important, macroeconomic events, such as market crashes or depressions.

One aspect of this type of analysis is that a rare or unusual event precipitates the escape episode. How rare is this event? In some analyses, it may seem implausible to wait for such a rare event to explain an important macroeconomic outcome. However, McGough (2006) suggests that in models that have escape dynamics, one may not have to wait for the rare precipitating event to occur to observe the escape dynamics. Instead, the escape can be triggered by a shock to the underlying fundamentals of the economy. In a version of Sargent's (1999) economy, the shock is a plausible shift in the natural rate of unemployment. ${ }^{23}$ The models with escape dynamics therefore have a certain instability, which might be activated by events other than the precise combination of shocks within the model necessary to generate an escape.

\section{Learning and Structural Change}

It has long been emphasized in economics that for one-time, unanticipated developments, learning makes a great deal of sense and rational expectations is inappropriate. That is, for structural change or other important, one-time shocks, the most appropriate analysis would include transitional learning dynamics as private sector and government officials learn the new equilibrium. The empirical evidence on the existence of structural change in macroeconomic time series is quite strong. For instance, most macroeconomic time series display a reduction in volatility after 1984, according to standard tests.

There is a rational expectations approach that one can take to study problems of this kind, such as the one used by Andolfatto and Gomme (2003). One can postulate that a key feature of the economy follows a regime-switching process, with given transition probabilities. One can then compute optimal behavior of the agents in the economy, given that underlying fundamentals may switch between two regimes. A full-information, rational expectations approach would endow the agents with knowledge of the current state along with the probability transition matrix and allow them to make optimal decisions given the uncertainty they face. A more realistic approach, and the one used by Andolfatto and Gomme (2003), asks the agents to infer the regime using available data and knowledge of the transition probabilities. The agents can solve this signal extraction prob-

\footnotetext{
${ }^{23}$ See Ellison and Yates (2006) for an alternative explanation of the
} timing of the escape dynamics described by Sargent (1999). 
lem optimally using Bayesian methods, and this is sometimes thought of as a type of "learning" analysis. However, in the context of the macroeconomic learning literature, this approach is really one of rational expectations given information available to the agents in the model. ${ }^{24}$

The rational expectations regime-switching approach is interesting, even brilliant, because it transforms an otherwise nonstationary problem into a stationary one, allowing the researcher to maintain a form of the rational expectations assumption. But I do not think this method is the right one for most types of structural change. Most of the shocks we think we observe are one-time permanent events, widely unexpected, such as the productivity slowdown from the 1970s to the 1990s in the United States. The nature of the event is that the current status quo changes permanently, but not to any well-defined alternative status quo. The new reality is learned only after the event has occurred. For this reason, I think subjecting available models to one-time permanent shocks, and allowing the agents in the model to learn the new equilibrium following the shock, is a better model of the nonstationarity we observe in the data. Of course, for recursive learning to tend to lead the economy toward the new equilibrium, the new equilibrium must be expectationally stable, and this expectational stability must extend to a wide enough neighborhood that the permanent shock does not destabilize the economy completely.

To implement this type of learning the literature has turned to constant-gain learning, inspired by the discussion in Sargent (1999). Most learning algorithms have today's perceptions as yesterday's perceptions plus a linear adjustment that is a function of the forecast error from the previous period. The coefficient multiplying the forecast error would typically be $1 / t$, to give equal weight to all past forecast errors. But an agent suspicious of structural change may wish to downweight past forecast errors and put more weight on more recent forecast errors. A simple method of doing

${ }^{24}$ There has been recent work that draws tighter connections between classical and Bayesian approaches to learning. See, for instance, Evans, Honkapohja, and Williams (2005) and Cogley and Sargent (2005). this is to change the gain from $1 / t$ to a small positive constant. A more sophisticated method is to use a Kalman filter or a nonlinear filter. ${ }^{25}$ The agent is then able to track changes in the environment without knowing exactly what the nature of those changes may be. Productivity growth may not simply be switching between high and low, but may visit many other regimes, some of which may never have been observed. The tracking idea equips agents with methods of coping in such an environment. It may well be a better model of structural change in the types of problems macroeconomists try to analyze.

For examples of economies with structural change and learning dynamics as I have described it, see Bullard and Duffy (2004), Bullard and Eusepi (2005), Lansing (2002), Milani (2005), Orphanides and Williams (2005), and Giannitsarou (2006).

\section{RESOURCES ON THE WEB}

In this paper, I have provided a limited survey of some of the issues and recent results in the macroeconomics learning literature. Much of this literature has provided commentary on monetary policy issues. The learnability criterion is just beginning to be widely used to assess key aspects of policy that have been difficult to address under a pure rational expectations approach.

This survey is far from comprehensive. There are many closely related issues that I have not attempted to address here. As of this writing, interested readers can consult the web page maintained by Chryssi Giannitsarou and Eran Guse at Cambridge University, "Adaptive Learning in Macroeconomics," which provides a more complete bibliography with up-to-date links: www.econ.cam.ac.uk/research/learning/.

\section{REFERENCES}

Adam, Klaus; Evans, George W. and Honkapohja, Seppo. "Are Hyperinflation Paths Learnable?"

\footnotetext{
${ }^{25}$ McCulloch (2005) provides an analysis of the connections between constant-gain algorithms and the Kalman filter.
} 
Journal of Economic Dynamics and Control, 2006 (forthcoming).

Andolfatto, David and Gomme, Paul. "Monetary Policy Regimes and Beliefs.” International Economic Review, February 2003, 44(1), pp. 1-30.

Arifovic, Jasmina. "The Behavior of the Exchange Rate in the Genetic Algorithm and Experimental Economies." Journal of Political Economy, June 1996, 104(3), pp. 510-41.

Arifovic, Jasmina. "Evolutionary Algorithms in Macroeconomic Models." Macroeconomic Dynamics, September 2000, 4(3), pp. 373-414.

Benhabib, Jess; Schmitt-Grohé, Stephanie and Uribe, Martin. "The Perils of Taylor Rules." Journal of Economic Theory, January/February 2001, 96(1-2), pp. 40-69.

Blanchard, Olivier J. and Kahn, Charles M. "The Solution of Linear Difference Models under Rational Expectations." Econometrica, July 1980, 48(5), pp. 1305-11.

Branch, William and Evans, George W. "Intrinsic Heterogeneity in Expectation Formation." Journal of Economic Theory, March 2006, 127(1), pp. 264-95.

Bray, Margaret. "Learning, Estimation, and the Stability of Rational Expectations." Journal of Economic Theory, April 1982, 26(2), pp. 318-39.

Bullard, James B. and Cho, In-Koo. "Escapist Policy Rules." Journal of Economic Dynamics and Control, November 2005, 29(11), pp. 1841-65.

Bullard, James B. and Duffy, John. "Learning and Structural Change in Macroeconomic Data." Working paper 2004-016A, Federal Reserve Bank of St. Louis, 2004.

Bullard, James B. and Eusepi, Stefano. "Did the Great Inflation Occur Despite Policymaker Commitment to a Taylor Rule?" Review of Economic Dynamics, April 2005, 8(2), pp. 324-59.

Bullard, James B. and Mitra, Kaushik. "Learning about Monetary Policy Rules.” Journal of Monetary Economics, September 2002, 49(6), pp. 1105-29.
Bullard, James B. and Mitra, Kaushik. "Learning, Determinacy, and Monetary Policy Inertia.” Journal of Money, Credit, and Banking, 2006 (forthcoming).

Clarida, Richard; Galí, Jordi and Gertler, Mark. "The Science of Monetary Policy: A New Keynesian Perspective." Journal of Economic Literature, December 1999, 37(4), pp. 1661-707.

Cho, In-Koo; Williams, Noah and Sargent, Thomas J. "Escaping Nash Inflation." Review of Economic Studies, January 2002, 69(1), pp. 1-40.

Cogley, Timothy and Sargent, Thomas J. “Anticipated Utility and Rational Expectations as Approximations of Bayesian Decision Making." Unpublished manuscript, New York University, March 2005.

DeCanio, Stephen. "Rational Expectations and Learning from Experience." Quarterly Journal of Economics, February 1979, 93(1), pp. 47-57.

Duffy, John and Xiao, Wei. "The Value of Interest Rate Stabilization Policies When Agents Are Learning." Working Paper, University of Pittsburgh, November 2005.

Duffy, John and Xiao, Wei. "Instability of Sunspot Equilibria in Real Business Cycle Models Under Adaptive Learning." Journal of Monetary Economics, 2006 (forthcoming).

Ellison, Martin and Yates, Tony. "Escaping Volatile Inflation." Working paper, University of Warwick and the Bank of England, January 2006.

Eusepi, Stefano. "Comparing Forecast-Based and Backward-Looking Taylor Rules: A 'Global' Analysis.” Staff Report No. 198, Federal Reserve Bank of New York, January 2005.

Evans, George W. "Expectational Stability and the Multiple Equilibria Problem in Linear Rational Expectations Models." Quarterly Journal of Economics, November 1985, 100(4), pp. 1217-33.

Evans, George W. and Honkapohja, Seppo. Learning and Expectations in Macroeconomics. Princeton, NJ: Princeton University Press, 2001. 
Evans, George W. and Honkapohja, Seppo.

"Expectations and the Stability Problem for Optimal Monetary Policies." Review of Economic Studies, October 2003a, 70(4), pp. 807-24.

Evans, George W. and Honkapohja, Seppo. "Adaptive Learning and Monetary Policy Design." Journal of Money, Credit, and Banking, December 2003b, 35(6, Part 2), pp. 1045-72.

Evans, George W. and Honkapohja, Seppo. "Policy Interaction, Expectations and the Liquidity Trap." Review of Economic Dynamics, April 2005, 8(2), pp. 303-23.

Evans, George W. and Honkapohja, Seppo. "Monetary Policy, Expectations, and Commitment." Scandanavian Journal of Economics, 2006 (forthcoming).

Evans, George W.; Honkapohja, Seppo and Mitra, Kaushik. “Notes on Agents' Behavioral Rules under Adaptive Learning and Recent Studies of Monetary Policy." Unpublished manuscript, University of Oregon, 2003.

Evans, George W.; Honkapohja, Seppo and Williams, Noah. "Generalized Stochastic Gradient Learning." Working Paper 2005-17, University of Oregon, 2005.

Evans, George W. and McGough, Bruce. "Monetary Policy, Indeterminacy and Learning." Journal of Economic Dynamics and Control, November 2005, 29(11), pp. 1809-40.

Ferrero, Giuseppe. "Monetary Policy and the Transition to Rational Expectations." Paper No. 19, Society for Computational Economics, Computing in Economics and Finance, August 2004.

Giannitsarou, Chryssi. "Heterogeneous Learning." Review of Economic Dynamics, October 2003, 6(4), pp. 885-906.

Giannitsarou, Chryssi. "Supply-side Reforms and Learning Dynamics." Journal of Monetary Economics, March 2006, 53(2), pp. 291-309.

Goodhart, Charles A.E. Remarks made at the conference "Expectations, Learning, and Monetary Policy," sponsored by the Deursche Bundesbank and the
Center for Financial Studies, Eltville, Germany, August 30-31, 2003.

Guse, Eran A. "Stability Properties for Learning with Heterogeneous Expectations and Multiple Equilibria." Journal of Economic Dynamics and Control, October 2005, 29(10), pp. 1623-42.

Hogarth, Robin M. and Reder, Melvin W., eds. Rational Choice: The Contrast Between Economics and Psychology. Chicago: University of Chicago Press, 1987.

Honkapohja, Seppo and Mitra, Kaushik. "Are Nonfundamental Equilibria Learnable in Models of Monetary Policy? " Journal of Monetary Economics, November 2004, 51(8), pp. 1743-70.

Honkapohja, Seppo and Mitra, Kaushik. "Performance of Inflation Targeting Based on Constant Interest Rate Projections." Journal of Economic Dynamics and Control, November 2005, 29(11), pp. 1867-92.

Kasa, Kenneth. "Learning, Large Deviations, and Recurrent Currency Crises.” International Economic Review, February 2004, 45(1), pp. 141-73.

Lansing, Kevin. "Learning About a Shift in Trend Output: Implications for Monetary Policy and Inflation.” Working Paper 2000-16, Federal Reserve Bank of San Francisco, July 2002.

Lucas, Robert E. Jr. "Adaptive Behavior and Economic Theory," in Robin M. Hogarth and Melvin W. Reder, eds., Rational Choice: The Contrast Between Economics and Psychology. Chicago: University of Chicago Press, 1987, pp. 217-42.

Marcet, Albert and Sargent, Thomas J. "Convergence of Least-Squares Learning Mechanisms in Self-referential Linear Stochastic Models." Journal of Economic Theory, August 1989a, 48(2), pp. 337-68.

Marcet, Albert and Sargent, Thomas J. "Convergence of Least-Squares Learning in Environments with Hidden State Variables and Private Information.” Journal of Political Economy, December 1989b, 97(6), pp. 1306-22.

Marimon, Ramon; McGrattan, Ellen and Sargent, Thomas J. "Money as a Medium of Exchange in an 
Economy with Artificially Intelligent Agents." Journal of Economic Dynamics and Control, May 1990, 14(2), pp. 329-73.

McCallum, Bennett T. "Issues in the Design of Monetary Policy Rules," in John B. Taylor and Michael Woodford, eds., Handbook of Macroeconomics. Volume 1C. New York: Elsevier, 1999, pp. 1483-530.

McCallum, Bennett T. "Multiple-Solution Indeterminacies in Monetary Policy Analysis." Journal of Monetary Economics, July 2003, 50(5), pp. 1153-75.

McCulloch, J. Huston. "The Kalman Foundations of Adaptive Least Squares, with Applications to U.S. Inflation.” Unpublished manuscript, Ohio State University, August 2005.

McGough, Bruce. "Shocking Escapes.” Economic Journal, 2006 (forthcoming).

Milani, Fabio. "Learning, Monetary Policy Rules, and Macroeconomic Stability." Unpublished manuscript, University of California, Irvine, July 2005.

Orphanides, Athanasios and Williams, John C. "The Decline of Activist Stabilization Policy: Natural Rate Misperceptions, Learning, and Expectations." Journal of Economic Dynamics and Control, November 2005, 29(11), pp. 1927-50.

Preston, Bruce. "Learning about Monetary Policy Rules When Long-Horizon Expectations Matter." International Journal of Central Banking, September 2005, 1(2), pp. 81-126.

Rotemberg, Julio J. and Woodford, Michael. "Interest Rate Rules in an Estimated Sticky Price Model," in John Taylor, ed., Monetary Policy Rules. NBER Conference Report series. Chicago: University of Chicago Press, 1999, pp. 57-119.

Sargent, Thomas J. The Conquest of American Inflation. Princeton, NJ: Princeton University Press, 1999.
Sargent, Thomas J. and Williams, Noah. "Impacts of Priors on Convergence and Escapes from Nash Inflation." Review of Economic Dynamics, April 2005, 8(2), pp. 360-91.

Svensson, Lars E.O. "Monetary Policy and Learning." Federal Reserve Bank of Atlanta Economic Review, Third Quarter 2003, 88(3), pp. 11-16.

Taylor, John B. "Discretion versus Policy Rules in Practice." Carnegie-Rochester Conference Series on Public Policy, December 1993, 39(0), pp. 195-214.

Vissing-Jorgensen, Annette. "Perspectives on Behavioral Finance: Does 'Irrationality' Disappear with Wealth? Evidence from Expectations and Actions," in Mark Gertler and Kenneth Rogoff, eds., NBER Macroeconomics Annual 2003. Cambridge, MA: MIT Press, 2004.

Williams, Noah. "Escape Dynamics in Learning Models.” Ph.D. Dissertation, University of Chicago, 2001.

Woodford, Michael. "Learning to Believe in Sunspots." Econometrica, March 1990, 58(2), pp. 277-307.

Woodford, Michael. "Optimal Monetary Policy Inertia.” Working Paper 7261, National Bureau of Economic Research, 1999.

Woodford, Michael. "The Taylor Rule and Optimal Monetary Policy." American Economic Review, May 2001, 91(2), pp. 232-37.

Woodford, Michael. Interest and Prices: Foundations of a Theory of Monetary Policy. Princeton, NJ: Princeton University Press, 2003a.

Woodford, Michael. "Multiple-Solution Indeterminacies in Monetary Policy Analysis: Comment." Journal of Monetary Economics, July 2003b, 50(5), pp. 1177-88. 
